\title{
ENRAIZAMENTO DE ESTACAS LENHOSAS E SEMILENHOSAS DE CULTIVARES DE AMEIXEIRA COM VÁRIAS CONCENTRAÇÕES DE ÁCIDO INDOLBUTÍRICO'
}

\author{
MAURO BRASIL DIAS TOFANELLI², NILTON NAGIB JORGE CHALFUN ${ }^{3}$, \\ ALEXANDRE HOFFMANN ${ }^{4}$, ANTÔNIO CHALFUN JÚNIOR ${ }^{5}$
}

\begin{abstract}
RESUMO - Para avaliar o potencial de enraizamento de estacas de ramos lenhosos e semilenhosos de cultivares de ameixeira (Carmesin, Gema de Ouro, Januária e Reubennel), utilizou-se aplicação exógena de ácido indolbutírico (IBA) em diferentes concentrações (0; 1000; 2000 e 3000 $\mathrm{mg} \mathrm{L}^{-1}$ ). O trabalho foi desenvolvido na Universidade Federal de Lavras (Lavras-MG), em 1997. Após os tratamentos, as estacas foram plantadas em areia lavada e colocadas em casa de sombreamento (lenhosas) e em casa de vegetação (semilenhosas) para enraizar. Foram avaliadas as variáveis porcentagem de enraizamento, número e comprimento de raízes. As maiores porcentagens de enraizamento foram obtidas com estacas semilenhosas da cultivar Januária (54,62\%). A aplicação de IBA favoreceu o enraizamento, a formação de maior número de raízes e o comprimento de raízes nas estacas semilenhosas.
\end{abstract}

Termos para indexação: propagação, IBA, Prunus salicina Lindl, Rosaceae

\section{USE OF THE INDOLBUTYRIC ACID ON PROPAGATION OF PLUM THROUGH HARDWOOD AND SOFTWOOD CUTTINGS}

\begin{abstract}
To evaluate the rooting potential of hardwood and softwood stem cuttings of four plum cultivars (Carmesin, Gema de Ouro, Januária, e Reubennel), was used exogenous applications of indolbutyric acid (IBA) in different concentrations (0, 1000, 2000 and $3000 \mathrm{mg} \mathrm{L}^{-1}$ ). The experimental was carried out at Universidade Federal de Lavras (Lavras, MG, Brazil) in 1997. After the treatments, the cuttings were planted in washed-sand. The hardwoods cuttings were placed in shade-house and the softwoods cuttings in greenhouse. Were evaluated the rooting percentage, root number and root length. The best results were obtained with softwood cuttings of the cultivar Januária $(54,62 \%)$. The rooting formation, root number and root length of the softwood cuttings were influenced by IBA.
\end{abstract}

Index terms: rooting, IBA, Prunus domestica Lindl, Rosaceae

\section{INTRODUÇÃO}

Na fruticultura mundial, a cultura da ameixeira exerce papel importante e, na América do Sul, destaca-se em países como o Chile. No Brasil, é realizada principalmente nos Estados de Santa Catarina, Rio Grande do Sul, Paraná e São Paulo. Em Minas Gerais, a produção ainda é pequena, mesmo havendo condições edafoclimáticas favoráveis para o cultivo, especialmente nas regiões sul deste Estado.

Um dos principais fatores que limita o aumento da produção nacional de ameixas, é sem dúvida o clima, pois, como citado por Dutra et al. (1998), a exploração de ameixa está em função da ocorrência de baixas temperaturas durante o inverno. No entanto, outros fatores também contribuem para a baixa produção brasileira desta fruta e, dentre as práticas essenciais para o sucesso da cultura, está a utilização de mudas de qualidade. A propagação da ameixeira é comumente realizada através da enxertia, utilizando-se do pessegueiro (Prunus persica (L.) Batsch) como porta-enxerto, o qual é multiplicado por sementes. Assim, há risco de ocorrer segregação genética deste material, produzindo pomares desuniformes quanto ao porte e longevidade. Além disso, de acordo com Kersten (1990), a vida útil da planta fica limitada devido ao pessegueiro possuir uma menor longevidade que a ameixeira.

A estaquia vem sendo empregada com sucesso na propagação de espécies frutíferas e é uma técnica de maior viabilidade econômica (Chalfun \& Hoffmann; Hoffmann et al.; citados por Antunes et al., 2000), porém, para a ameixeira, não têm sido obtidos resultados satisfatórios no Brasil, seja pelo baixo potencial de enraizamento apresentado por esta espécie, seja pelas deficiências nas técnicas de enraizamento. Com o objetivo de incrementar a capacidade de enraizamento de estacas de ameixeira, é que a aplicação de fitorreguladores sintéticos vem sendo amplamente utilizada. Entre os mais empregados, destaca-se o ácido indolbutírico (IBA), seja pela sua maior resistência à degradação por ação de raios solar, seja pela sua maior resistência ao ataque por ação biológica.

A capacidade de enraizamento de estaca varia de acordo com a espécie, tipo de estaca e cultivar (Tofanelli, 1999). Pasinato et al. (1998) demonstraram que, entre as cultivares de ameixeira

1 (Trabalho 117/2001). Recebido: 11/06/2001. Aceito para publicação: 20/12/2001.

2 Engo Agronō, Aluno de Pós-Graduação/Doutorado, DPV/Horticultura, FCA/UNESP, Cx.P. 237, 18603-970, Botucatu, SP. Emails: maurobdt@bol.com.br ou maurobdt@fca.unesp.br

3 Engํㅡㄹ Agrono, Doutor, Professor titular do DAG/UFLA, Cx.P. 37, 37200-000, Lavras, MG.

4 Eng $^{0}$ Agrono, Doutor, Pesquisador EMBRAPA - Uva e Vinho, Cx.P. 130, 95700-000, Bento Gonçalves, RS.

5 Eng ${ }^{\circ}$ Agronº , Aluno de Pós-Graduação/PhD, WAU, 26703 HÁ, Dreijenlaan, Wageningen, The Netherlands. 
All Producer, Ace, Sangal, Roxa de Itaquera, Frontier, Reubennel e Beauty, a cultivar Roxa de Itaquera foi a que apresentou maior porcentual de estacas lenhosas enraizadas $(76,1 \%)$ quando foram tratadas com 3000 $\mathrm{mg} \mathrm{L}^{-1}$ de IBA. Finardi \& Camelatto (1995) recomendaram o tratamento da base de estacas lenhosas da ameixeira Santa Rosa com solução de IBA, na concentração de $2000 \mathrm{mg} \mathrm{L}^{-1}$, durante 5 segundos para a obtenção de mudas. Porcentagens de até 68,22\% de enraizamento em estacas medianas da cultivar Frontier, colhidas em janeiro e de 65,99 \% nas colhidas em março, foram obtidas em experimento realizado por Dutra \& Kersten (1996), quando utilizaram a concentração de 3000mg $\mathrm{L}^{-1}$ de IBA.

O objetivo deste trabalho foi estudar o potencial de enraizamento de estacas lenhosas e semilenhosas de cultivares de ameixeira tratadas com ácido indolbutírico em diferentes concentrações.

\section{MATERIALEMÉTODOS}

O presente estudo foi desenvolvido no Pomar Didático da Universidade Federal de Lavras (UFLA), localizada no município de Lavras-MG. O experimento foi conduzido em duas fases: na primeira, foram utilizadas estacas lenhosas e na segunda, estacas semilenhosas.

O delineamento experimental adotado foi o inteiramente ao acaso, com quatro repetições e quinze estacas lenhosas e, devido à pouca disponibilidade de material, apenas dez estacas semilenhosas por parcela. Em cada fase, os tratamentos das parcelas seguiram um esquema fatorial $4 \times 2 \times 4$, envolvendo quatro cultivares (Carmesin, Gema de Ouro, Januária e Reubennel), dois tipos de estaca (lenhosa e semilenhosa) e quatro concentrações de $\operatorname{IBA}\left(0 ; 1000 ; 2000\right.$ e $\left.3000 \mathrm{mg} \mathrm{L}^{-1}\right)$.

As estacas de ameixeira foram coletadas de plantas com 8 a 9 anos de idade existentes na coleção de cultivares da UFLA. O material lenhoso foi coletado no final de junho de 1997, quando as plantas se encontravam em repouso vegetativo, aproveitando-se ramos descartados da poda de frutificação no inverno, e o semilenhoso em início de dezembro de 1997, utilizando-se de ramos de plantas em desenvolvimento vegetativo. Após a coleta, as estacas foram preparadas com comprimento de 15 a $20 \mathrm{~cm}$ e diâmetro de 5 a $7 \mathrm{~mm}$. Nas estacas semilenhosas, foram mantidas duas folhas cortadas ao meio por estaca. O substrato utilizado foi a areia lavada, colocada em sacos plástico pretos de polietileno medindo $10 \mathrm{~cm}$ de diâmetro por $20 \mathrm{~cm}$ de altura. Após o plantio, as estacas lenhosas foram colocadas em casa de sombreamento com $50 \%$ de sombra e as semilenhosas em casa de vegetação, onde permaneceram nestes ambientes por um período de 60 dias. Utilizou-se da irrigação manual periódica para as estacas lenhosas e a nebulização intermitente da casa de vegetação para as estacas semilenhosas.

As variáveis analisadas neste trabalho foram a porcentagem de estacas enraizadas, sendo consideradas as estacas que apresentassem pelo menos uma raiz adventícia emitida, o número médio de raízes primárias por estaca enraizada e o comprimento médio das raízes primárias por estaca enraizada. Os resultados foram analisados, comparando-se os níveis dos fatores cultivar e tipo de estaca através do teste de Duncan a 5\% de significância e os níveis do fator IBA através de análise de regressão. Efetuou- se transformação de dados segundo a equação arco-seno $\sqrt{x / 100}$ para os valores em porcentagem e $\sqrt{x+1}$ para os valores unitários, e, para isto, realizou-se o teste de normalidade no sistema SAS em ambos os experimentos.

\section{RESULTADOS E DISCUSSÃO}

A cultivar Januária (16,31\%) foi superior às demais quanto ao porcentual de estacas enraizadas (Tabela 1). Alguns fatores podem ter contribuído para este comportamento, como potencial genético de cada cultivar em formar raízes adventícias, balanço hormonal e consistência dos tecidos nas estacas (maior ou menor espessura do anel de esclerênquima). Além disso, as condições edafoclimáticas também influenciam na variabilidade do potencial de enraizamento de estaca entre as cultivares, pois, como relataram Kaundal et al. (1993) em estudo para avaliar o efeito de fitorreguladores sintéticos (IBA e Seradix $B_{3}$ ) na rizogênese em estacas lenhosas de pessegueiro ("Flodarsun", "Shan-i-Punjab", "Florda Red", "Sharbati" e "Nemaguard"), a exigência de horas de frio e a condição fisiológica da plantamatriz dependem do agroclima e poderiam influenciar na capacidade de formar raízes da estaca de acordo com as características de cada cultivar. Garrido et al. (1998), estudando a formação e crescimento de raízes em estacas de cravo (Diantus caryophillus L.) das cultivares Solar e Master, mencionaram que a sensibilidade e a resposta à auxina ao enraizamento depende de cada cultivar.

Também o tipo de estaca influenciou no porcentual de enraizamento (Tabela 1), ou seja, as estacas semilenhosas (16,63\%) foram superiores às lenhosas. O tipo de estaca é um dos principais fatores que influenciam na capacidade de formação de raízes em estaca de planta e, de acordo com Fachinello et al. (1995), estacas semilenhosas tendem a enraizar com mais facilidade, pois elas se apresentam menos lignificadas, não havendo, conseqüentemente, a presença de um anel de esclerênquima altamente lignificado, que dificultaria a emissão dos primórdios radiculares. Klein et al. (2000) consideraram a época de coleta da estaca (tipo de estaca) um fator crítico na determinação do porcentual de enraizamento. Sharma e Aier (1989), em trabalho desenvolvido para avaliar a formação de raízes em estacas de cultivares de ameixeiras japonesas e européias, observaram maior facilidade de enraizamento no material semilenhoso e atribuíram à baixa capacidade de formar raízes adventícias das estacas lenhosas, a presença do anel esclerenquimatoso e ao aumento de substâncias inibidoras durante a dormência. Já Rossal et al. (1997) relacionaram altos teores do precursor de auxina triptofano com a maior facilidade de enraizamento em estaca menos lignificada e, em adição, mencionaram que esta acumula reservas intensamente, que poderiam favorecer a formação das raízes.

Para estudo do efeito do IBA no enraizamento, realizaram-se regressões polinomiais para as interações significativas. Para a interação cultivar ' IBA, observou-se que as cultivares Carmesin e Gema de Ouro obtiveram maiores porcentuais de estacas enraizadas na concentração de $3000 \mathrm{mg} \mathrm{L}^{-1}$ de IBA $(29,58 \%$ e $36,82 \%$, respectivamente) (Figura 1). As cultivares Januária e Reubennel não obtiveram regressões significativas, Quanto à interação tipo de estaca 'IBA, as estacas semilenhosas apresentaram regressão significativa, obtendo o maior enraizamento na 
concentração de $3000 \mathrm{mg} \mathrm{L}^{-1}$ de IBA $(55,95 \%)$ (Figura 2). Tais resultados sugerem o estudo de concentrações de IBA superiores a $3000 \mathrm{mg} \mathrm{L}^{-1}$, pois poderiam proporcionar maiores enraizamentos. As estacas lenhosas não obtiveram regressão significativa. Este comportamento pode ser resultado do balanço hormonal favorável ao enraizamento ocasionado pela maior dosagem do fitorregulador. Biasi et al. (2000) observaram que a maior concentração de IBA utilizada $\left(2000 \mathrm{mg} \mathrm{L}^{-1}\right)$ proporcionou maior enraizamento das estacas semilenhosas da cultivar de pessegueiro Coral $(83,37 \%)$.

Para a variável número de raízes, observou-se efeito significativo de todos os fatores, inclusive da interação tripla. Verifica-se, na Figura 3, que apenas as estacas semilenhosas das cultivares Carmesin, Gema de Ouro e Januária (máximos de 2,98; 3,08 e 5,47; respectivamente, com $3000 \mathrm{mg} \mathrm{L}^{-1}$ de IBA) obtiveram regressões significativas ao nível de $5 \%$ de probabilidade. Rufato \& Kersten (2000) também observaram que o IBA aumentou o número de raízes em estacas lenhosas de pessegueiro das cultivares Esmeralda e BR2. Para estes autores, isso ocorreu pela característica do fitorregulador em estimular a emissão de raízes.
Para a variável comprimento médio de raízes, houve efeito significativo do fator cultivar (Tabela 1), onde as cultivares Januária e Gema de Ouro promoveram os maiores comprimentos de raízes $(1,88$ e $1,81 \mathrm{~cm}$, respectivamente). Houve também efeito do tipo de estaca, onde as estacas semilenhosas $(2,44 \mathrm{~cm})$ foram superiores às lenhosas $(0,13 \mathrm{~cm})$ (Tabela 1$)$. Para a interação cultivar' tipo de estaca, observaram-se resultados superiores de comprimento de raízes nas estacas semilenhosas das cultivares Januária e Gema de Ouro ( 4,75 e 3,88cm, respectivamente). O efeito do IBA foi semelhante ao ocorrido para o enraizamento (Figuras 1 e 4; Figuras 2 e 5), pois, em ambas as variáveis, o IBA influenciou nas cultivares Carmesin e Gema de Ouro para a interação cultivar 'IBA e somente nas estacas semilenhosas para a interação tipo de estaca ' IBA. Esta relação entre enraizamento e comprimento de raízes é comprovada pela alta significância demonstrada pela análise de correlação simples entre estas duas variáveis (Tabela 2). Na cultivar Carmesin, houve aumento linear no comprimento de raízes até $3000 \mathrm{mg} \mathrm{L}^{-1} \mathrm{de}$ IBA $(2,45 \mathrm{~cm})$ e, na cultivar Gema de Ouro, o aumento obedeceu a uma regressão quadrática com o máximo de $3,51 \mathrm{~cm}$ na concen-

TABELA 1 - Porcentuais de enraizamento de estacas lenhosas e semilenhosas de cultivares de ameixeira tratadas com diferentes concentrações de IBA. Lavras-UFLA, 2001.

\begin{tabular}{|c|c|c|c|c|c|c|c|c|c|}
\hline \multirow{2}{*}{ Cultivares } & \multicolumn{3}{|c|}{ Enraizamento (\%) } & \multicolumn{3}{|c|}{ Número de raízes } & \multicolumn{3}{|c|}{ Comprimento de raízes (cm) } \\
\hline & & Lenh & Semil & & Lenh & Semil & & Lenh & Semil \\
\hline Carmesin & $2,27 \mathrm{bc}$ & $0,40 \mathrm{aB}$ & $5,65 \mathrm{cA}$ & $0,44 \mathrm{~b}$ & $0,27 \mathrm{aA}$ & $0,62 \mathrm{bA}$ & $0,43 b$ & $0,14 \mathrm{aA}$ & $0,76 \mathrm{bA}$ \\
\hline le Ouro & $5,19 b$ & $0,78 \mathrm{aB}$ & & & $0,42 \mathrm{aA}$ & & & $0,31 \mathrm{aB}$ & $8 \mathrm{aA}$ \\
\hline Januária & $16,31 \mathrm{a}$ & $0 \mathrm{aB}$ & $54,62 \mathrm{aA}$ & $1,69 \mathrm{a}$ & $0 \mathrm{aB}$ & $4,19 \mathrm{aA}$ & $1,88 \mathrm{a}$ & $0,10 \mathrm{aB}$ & $4,75 \mathrm{aA}$ \\
\hline Reubennel & $2,04 \mathrm{c}$ & $0,24 \mathrm{aB}$ & $5,53 \mathrm{cA}$ & $0,50 \mathrm{~b}$ & $0,24 \mathrm{aA}$ & $0,50 \mathrm{bA}$ & $0,60 \mathrm{~b}$ & $0 \quad \mathrm{aB}$ & $1,20 \mathrm{bA}$ \\
\hline & & $0,25 \mathrm{~B}$ & $16,63 \mathrm{~A}$ & & $0,23 \mathrm{~B}$ & $1.45 \mathrm{~A}$ & & $0,13 \mathrm{~B}$ & $2,44 \mathrm{~A}$ \\
\hline
\end{tabular}

Médias seguidas na coluna por letras minúsculas e maiúsculas, na linha, diferem entre si pelo teste de Duncan, ao nível de 5\% de significância. Lenh - estacas lenhosas; Semil - estacas semilenhosas.

TABELA 2 - Correlação entre as variáveis enraizamento e número de raízes nas estacas de quatro cultivares de ameixeira. LavrasUFLA, 2001.

\begin{tabular}{lcc}
\hline Variáveis & Coeficiente de correlação & $\mathrm{t}$ \\
\hline Enraizamento $\times$ Número de Raízes & 0,8057851 & $15,2732 * *$ \\
\hline Enraizamento $\times$ Comprimento de Raiz & 0,8181973 & $15,9743 * *$ \\
\hline Número $\times$ Comprimento de Raiz & 0,6056825 & $8,5443 * *$ \\
\hline
\end{tabular}

** correlação significativa ao nível de $1 \%$ de probabilidade

- $\rightarrow$ Carmesin $\times$ Gema de Ouro

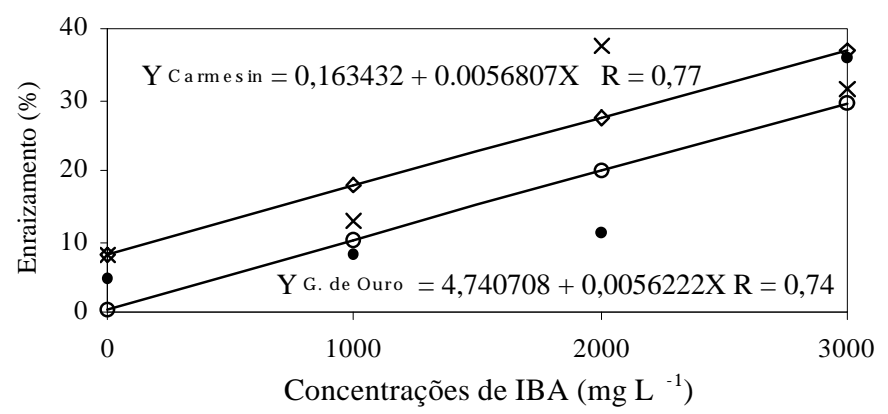

FIGURA 1 - Efeito do IBA no enraizamento de estacas de ameixeira das cultivares Carmesin e Gema de Ouro em função da interação cultivar $\times$ IBA. Médias das estacas lenhosas e semilenhosas. Lavras-UFLA, 2001.

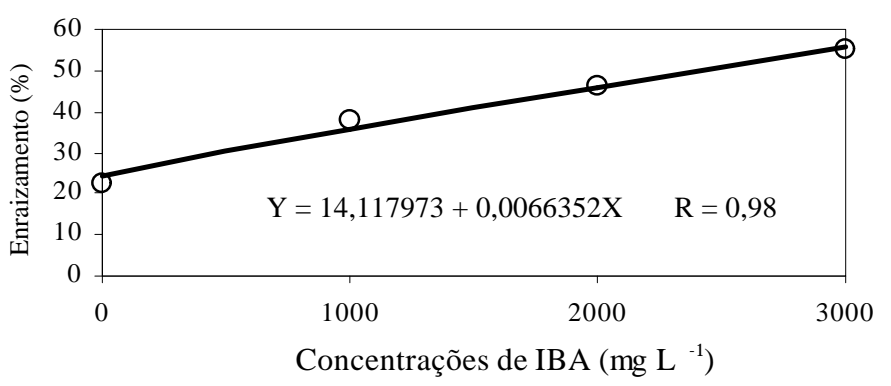

FIGURA 2 - Efeito do IBA no enraizamento de estacas semilenhosas de ameixeira em função da interação tipo de estaca $\times$ IBA. Médias das cultivares Carmesin, Gema de Ouro, Januária e Reubennel. Lavras-UFLA, 2001. 


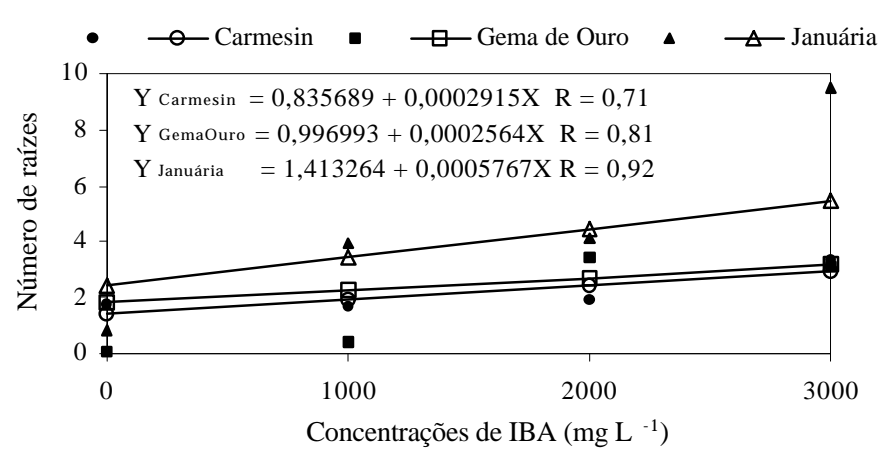

FIGURA 3 - Efeito do IBA no número de raízes por estaca semilenhosa enraizada de ameixeira das cultivares Carmesin, Gema de Ouro e Januária em função da interação cultivar $\times$ tipo de estaca $\times$ IBA. Lavras-UFLA, 2001.

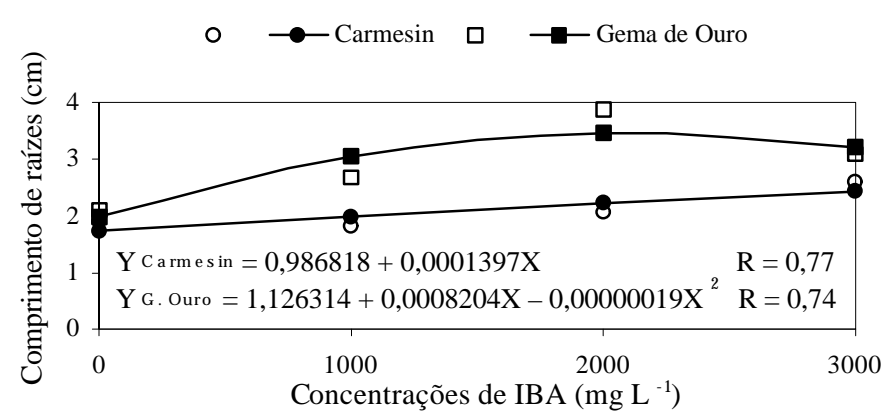

FIGURA 4 - Efeito do IBA no comprimento de raízes de estacas enraizadas de ameixeira das cultivares Carmesin e Gema de Ouro em função da interação cultivar $\times$ IBA. Médias das estacas lenhosas e semilenhosas. Lavras-UFLA, 2001.

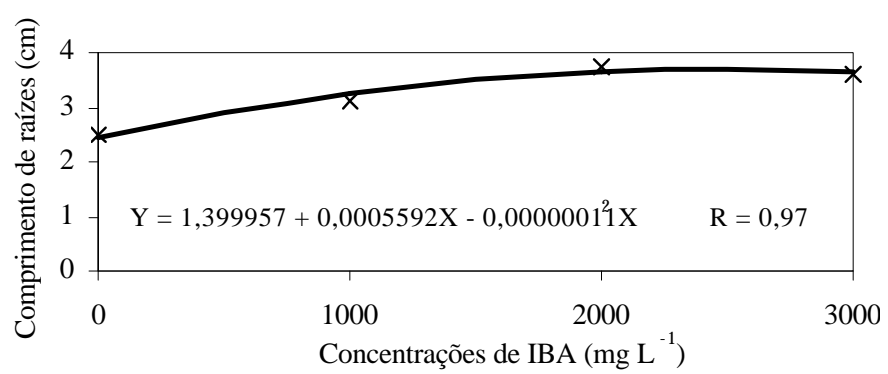

FIGURA 5 - Efeito do IBA no comprimento de raízes de estacas semilenhosas enraizadas de ameixeira em função da interação tipo de estaca $\times$ IBA. Médias das cultivares Carmesin, Gema de Ouro, Januária e Reubennel. Lavras-UFLA, 2001.

tração de 2158,95mg L-1 (Figura 4). A regressão quadrática para tipo de estaca ' IBA demonstrou um máximo de comprimento de raízes de 3,68cm com 2541,82 $\mathrm{mg} \mathrm{L}^{-1}$ (Figura 5).

Importantes correlações puderam ser observadas entre os parâmetros estudados neste experimento (Tabela 2), pois verificou-se que quanto maior o enraizamento, maior o número e comprimento de raízes.

\section{CONCLUSÕES}

A cultivar, IBA e o tipo de estaca influenciam no porcentual de enraizamento. A estaca semilenhosa das ameixeiras possui maior capacidade de enraizamento do que a lenhosa, e a concentração de $3000 \mathrm{mg} \mathrm{L}^{-1}$ de IBA foi mais eficiente na promoção do enraizamento. A propagação da ameixeira, utilizando-se de estacas semilenhosas da cultivar Januária, constitui-se uma alternativa para a obtenção de mudas.

\section{REFERÊNCIAS BIBLIOGRÁFICAS}

ANTUNES, L.E.C.; CHALFUN, N.N.J.; REGINA, M. de A. Propagação de cultivares de amoreira-preta (Rubus spp) através de estacas lenhosas. Revista Brasileira de Fruticultura, Jaboticabal, v.22, n.2, p.195-199, ago 2000.

BIASI, L.A.; STOLTE, R.E.; SILVA, M. da S. Estaquia de ramos semilenhosos de pessegueiro e nectarina. Revista Brasileira de Fruticultura, Jaboticabal, v.22, n.3, p.421-425, dez 2000.

DUTRA, L.F.; KERSTEN, E. Efeito do substrato e da época de coleta de ramos no enraizamento de estacas de ameixeira (Prunus salicina Lindl). Ciência Rural, Santa Maria, v. 26, n.3, p.361-366, jan/abr 1996.

DUTRA, L.F.; TONIETTO, A.; KERSTEN, E. Efeito da aplicação de ethefon em ameixeira (Prunus salicina Lindl) e do IBA no enraizamento de suas estacas. Scientia Agricola, Piracicaba, v.55, n.2, p.296-304, mai/ago 1998

FACHINELLO, J.C.; HOFFMANN, A.; NACHTIGAL, J.C.; KERSTEN, E., FORTES, G.R.L. Propagação de plantas frutíferas de clima temperado. Pelotas: UFPEL, 1995. 179p.

FINARDI, N.L., CAMELATTO, D. Obtenção de mudas de ameixeira cv. Santa Rosa a partir de estacas lenhosas. (Comunicado Técnico) Pelotas: EMBRAPA/CPACT, 1995. Pelotas, 4p.

GARRIDO, G.; CANO, E.A.; ACOSTA, M.; SÁNCHEZ-BRAVO, J. Formation and growth of roots in carnation cuttings influence of storage period and auxin treatment. Scientia Horticulture, Amisterdam, v.74, n.3, p.219-231, mai 1998.

KAUNDAL, G.S.; KANWAR, J.S.; BRAR, S.S.; DEOL, I.S.; CHANANA, Y.R. Effect of growth regulators on the rhizogenesis of peach cultivars. Indian Journal of Horticulture, India, v.50, n.4, p.318-326, 1993.

KERSTEN, E. Efeito do boro, zinco e ácido indolbutírico no enraizamento de estacas de dois cultivares de ameixeira (Prunus salicina, Lindl.). 1990. 109f. Tese-(Doutorado em solos e nutrição de plantas) - Escola Superior de Agricultura "Luiz de Queiroz, Universidade de São Paulo, Piracicaba, 1990.

KLEIN, J.D.; COHEN, S.; HEBBE, Y. Seasonal variation in rooting ability of myrtle (Myrtus communis L.) cuttings. Scientia Horticulture, Amsterdam, v.83, n.1, p.71-76, jan 2000. 
PASINATO, V.; NACHTIGAL, J.C.; KERSTEN, E. Enraizamento de estacas lenhosas de cultivares de ameixeira (Prunus spp.), em condições de campo. Scientia Agricola, Piracicaba, v.55, n.2, p.265-268, mai/ago 1998.

ROSSAL, P.A.L.; KERSTEN, E., CONTER, P.F. Estudo comparativo da evolução do nível de triptofano em ramos de ameixeira (Prunus salicina Lindl.). Scientia Agricola, Piracicaba, v.54, n.3, set/dez 1997.

RUFATO, L.; KERSTEN, E. Enraizamento de estacas de pessegueiro (Prunus persica (L.) Batsch), cvs Esmeralda e BR2, submetidas à estratificação e ao ácido indolbutírico. Revista Brasi- leira de Fruticultura, Jaboticabal, v.22, n.2, p.191-194, ago 2000.

SHARMA, S.D.; AIER, N.B. Seasonal rooting behaviour of cuttings of plum cultivars as influenced by IBA treatments. Scientia Horticulturae, Amsterdam, v.40, n.4, p.297-303, nov 1989.

TOFANELLI, M. B. D. Enraizamento de estacas lenhosas e semilenhosas de cultivares de pessegueiro em diferentes concentrações de ácido indolbutírico. 1999. 87f. Dissertação (Mestrado em Agronomia) - Universidade Federal de Lavras, Lavras, 1999. 